\title{
Effects of Earlier Mobilisation on Critically Ill Patients
}

\author{
Alves A.I. ${ }^{\text {, }}$, Freitas C. ${ }^{2}$, Viveiros A. ${ }^{3}$, Ribeiro L. ${ }^{4}$, Gonçalves R. ${ }^{5}$, Andrade M. ${ }^{6}$, Ascensão H. ${ }^{7}$, Teles L. ${ }^{8}$ \\ 1. MSc of in Food Consumption Science, MSc and Specialist in Medical-Surgical Nursing, DSc in Nursing, functions in the Intensive Care Unit of Hospital Dr. Nélio Mendonça, Funchal, Madeira, Portugal.

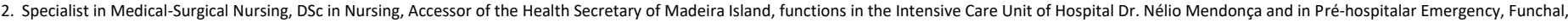 \\ Madeira, Portugal. \\ 3. MSc DSc in Management in Nursing, Specialist in Medical-Surgical Nursing and in Intensive Care and Resuscitation, Chief of the Intensive Care Unit of Hospital Dr. Nélio Mendonça, Funchal, Madeira, Portugal.

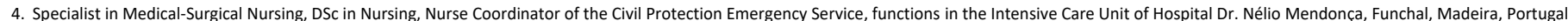 \\ 5. Specialist in Rehabilitation Nursing, DSc in Nursing, functions in the Intensive Care Unit of Hospital Dr. Nélio Mendonça, Funchal, Madeira, Portugal. \\ 6. Specialist in Medical-Surgical Nursing, DSc in Nursing, functions in the Intensive Care Unit of Hospital Dr. Nélio Mendonça, Funchal, Madeira, Portugal. \\ 7. Specialist in Rehabilitation Nursing, DSc in Nursing, functions in the Intensive Care Unit of Hospital Dr. Nélio Mendonça, Funchal, Madeira, Portugal. \\ 8. DSc in Nursing, functions in the Intensive Care Unit of Hospital Dr. Nélio Mendonça, Funchal, Madeira, Portugal.
}

Corresponding author (1): e-mail: anaigalves@gmail.com

DOI: $10.29322 / I J S R P .10 .12 .2020 . p 10810$

http://dx.doi.org/10.29322/IJSRP.10.12.2020.p10810

\begin{abstract}
Introduction: An intensive care unit (ICU) provides patients with advanced life support, where they stay from hours to months to stabilise and survive. Early mobilisation has proven to be a safe and viable technique that provides hemodynamic benefits, avoids the effects of immobility and contributes to the best physical and functional outcomes for patients. Objective: The aim of this study is to clarify the importance of early mobilisation (EM) in critically ill patients. Material and Methods: A systematic review of the literature by mobilizing the descriptors: "Critical patient", "Early mobilisation" and "Nursing ". Were selected databases imaginable, between 2014-2020, included for analysis seven articles. Results and Discussion: Results and discussion: In most studies it was found that the general form, this practice provides increased muscle strength, increased maximum inspiratory pressure, shorter duration of mechanical ventilation, shorter hospital stay and better quality of life. The seven studies identified recognized the importance of early mobilization as it can facilitate the functional rehabilitation of these patients by promoting increased muscle strength and greater participation in daily activities, but some studies also identified challenges that need to be addressed. Conclusion: Early mobilization contributes to improve the patient's functional capacity and quality of life, both in the hospital environment and in the post-discharge period. It has been shown that patients who are mobilized early in a safe and practical manner have advantages in the face of the disease. This behavior helps to reduce muscle weakness acquired through immobility in bed and enables faster functional recovery, shorter weaning and shorter hospital and intensive care stays.
\end{abstract}

Keywords: "Critical patient", "Early mobilisation" and "Nursing".

\section{INTRODUCTION}

$\mathbf{I}_{\mathrm{to}}^{\mathrm{n}}$ $\mathrm{n}$ recent decades, the number of patients admitted to intensive care units (ICUs) has increased. At the same time, the growing ability to support vital functions together with the effectiveness of new therapies has increased the survival rates of critically ill patients. In this context, a critically ill patient is a person whose life is threatened by the failure or imminent failure of one or more vital functions and whose survival depends on advanced means of monitoring, observation and therapy (Regulamento ${ }^{\circ} 124$, de 18 de Fevereiro. Diário da República nº 35/11 - II Série. Ordem dos Enfermeiros. Lisboa, Portugal).

The patients loss of mobility in hospital has negative effects on several organ systems, including the respiratory, cardiovascular, skin, muscle and skeletal systems, as well as on patients in ICUs (Silva et al, 2010). Pulmonary complications such as atelectasis, hypoxemia, pulmonary embolism and pneumonia are among the most common and lead to longer retention times and higher mortality (Soares, et al, 2011). In the last two decades, progress has been made both in the field of critically ill patients and in the field of mechanical ventilation, which has led to an extension of the survival time of critically ill patients (Dantas et al., 2012; Terra et al., 2012). Lack of exercise in bed is associated with the development of musculoskeletal dysfunctions such as muscle weakness and osteoarticular deformities among other complications that limit the functionality and quality of life of these patients after discharge from hospital (Mattos, 2011). Such immobility in the critically ill patient is an important limitation that is associated with a loss of innervation and a decrease in muscle mass (Mattos, 2011). Such immobility in the critically ill patient is an important limitation that leads to a loss of innervation and a decrease in muscle mass (Feliciano, et. al., 2012). The start of rehabilitation of critically ill patients in intensive care units was a research topic and was considered an important part of a care plan. In the field of functional rehabilitation, EM of critically ill patients has been proposed as an important therapy to modify the risk of developing secondary diseases that affect their physical and functional morbidity, as these are associated with the loss of muscle strength leading to acquired weakness (Morris et al., 2011). EM in the intensive care unit aims to maintain or increase the muscle strength and physical function of the patient. It includes progressive therapeutic activities such as bedside mobility exercises, bedside sitting, transfer to a chair and walking (Mota e Silva, 2012, Rocha et al, 2012). A variety of therapeutic exercises that prevent muscle weakness and deformities and also reduce the use of aids during 
hospitalisation. The harmful effects of bed rest and the benefits of early mobilisation have been recognised in hospital patients. When referring to "early", it refers to the concept that mobilisation activities begin immediately after the stabilisation of important physiological changes, rather than after the absence of mechanical ventilation or discharge from the ICU (Mota e Silva, 2012). According to Grap and McFetridge (2012), EM (also referred to as progressive mobility) describes a pattern of increasing activity that begins with passive mobilisation and extends to walking, which begins immediately after hemodynamic and respiratory stabilisation, usually within 24-48 hours of admission to the ICU. However, the EM of critically ill patients has several peculiarities inherent to the context of action and uses different activities depending on the individual needs of the patients.

One of the aims of patient mobilization is to provoke a respiratory and cardiovascular response in the individual, which is why it is essential to consider patient safety before starting treatment (Oliveira and Silveira, 2010). Knowledge of past and current clinical history shows how the patient's respiratory and cardiovascular reserve can be a limiting factor in activity and what signs and symptoms should be monitored during mobilization (Oliveira and Silveira, 2010). In search of the best available evidence to improve the quality of care, a systematic literature review was carried out to identify the impact of EM in the functional rehabilitation of patients admitted to intensive care units.

\section{MATERIALS AND METHODS}

A systematic review of the literature is one of the research methods used in the practice of evidence-based research, and its purpose is to collect and summarize research findings on a particular topic in a systematic and orderly manner, thereby contributing to knowledge about the topic (Mendes et al., 2008; Benefield, 2003). The method used was based on the strategy PICO (acronym for patient, intervention, comparation and "outcomes"). In this way it maximizes the inclusion of relevant information in different databases, focusing on the research object and avoiding unnecessary searches (Santos, Pimenta e Nobre, 2007).

With strict attention to all the steps necessary for the application of this method, in the period between May and September 2020, a protocol has been developed to identify studies of interest for this work, consisting of a search in the search engines: Ebsco and BONline, and in the following databases: CINAHL Plus, PubMed/ MEDLINE, LILACS, Scielo, Web of Science, ScienceDirect and Repository of Scientific Open Access of Portugal.

A search strategy using the following descriptors was used to identify relevant studies: Critical Patient AND Early Mobilisation AND Nursing. After all these protocol requirements had been met, some articles that did not meet the requirements were discarded and a reductive process was methodically developed.

\section{RESULTS}

It was selected for the study seven articles that follow in Table 1.

Table 1: Description of selected studies and main results of investigations

\begin{tabular}{|c|c|c|}
\hline Study & Author(s)/ Year & Main Results \\
\hline $\begin{array}{l}\text { E1: "The Effects of } \\
\text { Early Mobilization on } \\
\text { Patients Requiring } \\
\text { Extended Mechanical } \\
\text { Ventilation Across } \\
\text { Multiple ICUs" }\end{array}$ & $\begin{array}{l}\text { Miguel Escalon, } \\
\text { Ann Lichtenstein, } \\
\text { Elliot Posner, Lisa } \\
\text { Spielman, Andrew } \\
\text { Delgado, Stephanie } \\
\text { Kolakowsky-Hayner; } \\
2020 .\end{array}$ & $\begin{array}{l}\text {-It was verified that EM was evaluated in intensive care units based on the number of physiotherapy consultations, } \\
\text { length of stay, individual treatment sessions using functional results and follow-up visits. } \\
\text {-EM protocol in all intensive care units led to a significant increase in the number of physiotherapy consultations, } \\
\text { a significant reduction in the number of intensive care units and the total length of stay, significantly shorter days } \\
\text { for conducting physiotherapy and a significantly higher follow-up rate for physiotherapy. } \\
\text {-It was concluded that the mobilization of people in an intensive care unit reduces the length of stay and hospital } \\
\text { costs. } \\
\text {-With an interdisciplinary team that plans, implements and evaluates the individual phases of the program, a } \\
\text { successful EM program can be implemented simultaneously in all intensive care units and bring about changes } \\
\text { in patients requiring longer mechanical ventilation. }\end{array}$ \\
\hline $\begin{array}{l}\text { E2: "Early } \\
\text { Mobilization } \\
\text { Interventions in the } \\
\text { Intensive Care Unit: } \\
\text { Ongoing and } \\
\text { Unpublished } \\
\text { Randomized Trials" }\end{array}$ & $\begin{array}{lr}\text { Janane } & \text { Maheswaran, } \\
\text { Jake } & \text { Fromowitz, } \\
\text { Michael } & \text { Goldfarb; } \\
2020 & \end{array}$ & $\begin{array}{l}\text {-In this study the primary EM interventions were standard physiotherapeutic activities, cycling and electrical } \\
\text { muscle stimulation. Only one study involved a nurse led by EM. The most common assessment tool was the 6- } \\
\text { minute walk test. } \\
\text {-Primary outcome measures were physiological, clinical, patient-centered and resource consumption in health } \\
\text { care. Most of the studies included post ICU follow-up up to one year after hospitalization. } \\
\text {-The results of this study have shown that EM has the potential to improve outcomes in intensive care, but current } \\
\text { data on its effectiveness are limited. } \\
\text {-The studies identified may provide further information on what modalities EM may be feasible and what short } \\
\text { and long-term benefits may result. } \\
\text {-This review has identified areas that can be further explored, such as looking at specific study populations and } \\
\text { finding more innovative EM delivery methods. } \\
\text {-Discovered studies will further the evidence base for the effectiveness of EM There is a need for studies that } \\
\text { address specific patient groups that could benefit from EM, such as older adults and heart patients, and for novel } \\
\text { EM delivery strategies, such as nurse-led EM. }\end{array}$ \\
\hline
\end{tabular}




\begin{tabular}{|c|c|c|}
\hline $\begin{array}{l}\text { E3: "Early } \\
\text { mobilization of } \\
\text { critically ill patients in } \\
\text { the intensive care unit: } \\
\text { A systematic review } \\
\text { and meta-analysis" }\end{array}$ & $\begin{array}{l}\text { Lan Zhang, Weishu } \\
\text { Hu, Zhiyou Cai, Jihong } \\
\text { Liu, Jianmei Wu, } \\
\text { Yangmin Deng, } \\
\text { Keping Yu, Xiaohua } \\
\text { Chen, Li Zhu, Jingxi } \\
\text { Ma and Yan Qin; } 2019\end{array}$ & $\begin{array}{l}\text {-In this studie was possible verify that EM decreased the incidence of ICU-acquired weakness at hospital } \\
\text { discharge, increased the number of patients who were able to stand, increased the number of ventilator-free days, } \\
\text { during hospitalization, increased the distance the patient was able to walk unassisted at hospital discharge, and } \\
\text { increased the discharged-to-home rate. } \\
\text {-The mortality (28-day, ICU and hospital) and adverse event rates were moderately increased by EM, but the } \\
\text { differences were statistically non-significant. However, due to the substantial heterogeneity among the included } \\
\text { studies, and the low quality of the evidence, the results of this study should be interpreted with caution. } \\
\text {-It was possible to conclude that EM appears to decrease the incidence of acquired weakness in intensive care, } \\
\text { improve the functional capacity and increase the number of ventilator-free days and the discharged-to-home rate } \\
\text { for patients with a critical illness in the ICU setting. }\end{array}$ \\
\hline $\begin{array}{l}\text { E4: "Clinical attitudes } \\
\text { and perceived barriers } \\
\text { to early mobilization } \\
\text { of critically ill patients } \\
\text { in adult intensive care } \\
\text { units" }\end{array}$ & $\begin{array}{l}\text { Paula Caitano Fontela, } \\
\text { Luiz Alberto } \\
\text { Forgiarini, } \\
\text { Gilberto Friedman, } \\
2018\end{array}$ & $\begin{array}{l}\text {-It was verified favorable attitudes toward EM included recognition that its benefits for patients under mechanical } \\
\text { ventilation exceed the risks for both patients and staff, that EM should be routinely performed via nursing and } \\
\text { physical therapy protocols, and readiness to change the parameters of mechanical ventilation and reduce sedation } \\
\text { to facilitate the EM of patients. } \\
\text {-The main barriers mentioned were the unavailability of professionals and time to mobilize patients, excessive } \\
\text { sedation, delirium, risk of musculoskeletal self-injury and excessive stress at work. } \\
\text {-It could be concluded that the participants were aware of the benefits of EM and had a positive attitude towards } \\
\text { its use. However, the actual performance of EM was perceived as challenging, mainly due to the lack of } \\
\text { professionals and time, excessive sedation, delirium, risk of musculoskeletal self-harm and excessive stress at } \\
\text { work. }\end{array}$ \\
\hline $\begin{array}{l}\text { E5:" Early } \\
\text { Mobilization of } \\
\text { Patients in Intensive } \\
\text { Care: Organization, } \\
\text { Communication and } \\
\text { Safety Factors that } \\
\text { Influence Translation } \\
\text { into Clinical Practice" }\end{array}$ & $\begin{array}{lr}\text { Carol L. Hodgson, } \\
\text { Elizabeth } & \text { Capell, } \\
\text { Claire J. Tipping; } 2018\end{array}$ & $\begin{array}{l}\text {-It has been verified that there is currently a gap between ICU professionals who want to implement EM based } \\
\text { on the current evidence and professionals who believe EM is an intervention that should be tested in a large } \\
\text { patient-centered study to determine long-term outcomes. } \\
\text {-Despite the publication of safety recommendations and clinical practice guidelines, the implementation of EM } \\
\text { in the ICU remains a challenge, as limited information on safe levels of vasoactive support, persistent evidence } \\
\text { of oversedation of mechanically ventilated patients and poor staffing levels limit the ability to implement EM. } \\
\text {-Based on current evidence, EM is safe during mechanical ventilation, but conservative management of ICU } \\
\text { patients leads to a culture of bed rest. Some of the driving forces for clinical decisions can be modified, with } \\
\text { better adherence to sedation and mobilization protocols, clinical leadership, and increased staff resources and } \\
\text { training. } \\
\text { - However, EM should be tested in a patient-centered study with evaluation of long-term results before } \\
\text { implementation. }\end{array}$ \\
\hline $\begin{array}{l}\text { E6: "Early } \\
\text { mobilization: Why, } \\
\text { what for and how?" }\end{array}$ & $\begin{array}{l}\text { Miranda Rocha, B.P. } \\
\text { Martinez, } \\
\text { Maldaner da Silva, } \\
\text { L.A. Forgiarini Junior; } \\
\text { (2017) }\end{array}$ & $\begin{array}{l}\text {-EM strategies in intensive care units can lead to the prevention and reduction of polyneuromyopathy in critical } \\
\text { patients, to an improvement in the quality of life, to a shortening of the intensive care and hospital stay and to } \\
\text { lower mortality during hospitalization. } \\
\text {-However, it is known that factors such as the protocol used, the population involved in the studies, the timing of } \\
\text { the strategy, the severity of the patients and various barriers directly influence the results. } \\
\text {-Although sometimes mobilization is not applied, programs that focus on specific populations, such as patients } \\
\text { with weakness due to immobility and with preserved neuromuscular excitability, may have more positive effects } \\
\text { from such treatment. }\end{array}$ \\
\hline $\begin{array}{l}\text { E7: "Early } \\
\text { Mobilisation in ICU: } \\
\text { From Concept to } \\
\text { Reality - Four Steps to } \\
\text { Change Patient } \\
\text { Outcomes" }\end{array}$ & $\begin{array}{l}\text { Jean-Michel } \\
\text { Constantin; } 2016\end{array}$ & $\begin{array}{l}\text {-Research shows that the short-term effects of EM on delirium and patient feeling, as a hope for a long-term } \\
\text { improvement in quality of life, are sufficient encouragement for intensive care unit staff. } \\
\text {-It also shows that team motivation is probably not an issue in the process of EM; team motivation is only the } \\
\text { result of the process. } \\
\text {-motivation could, however, be included in the first plan if fears, doubts and an insufficient workload were } \\
\text { eliminated by a protocol that includes an algorithm for patient-centered care with an appropriate education } \\
\text { program, which is part of the early comfort of using analgesia, minimal sedatives and maximum humane care. }\end{array}$ \\
\hline
\end{tabular}

\section{DISCUSSION}

From the analysis of the selected studies it can be concluded that early mobilization in critically ill patients is safely possible and can begin immediately after their physiological stabilization. According to the literature in all studies, prolonged immobilization of critically ill patients has negative effects on the musculoskeletal, cardiovascular and respiratory systems, skin and cognition (Mah et al, 2013, Parry et al, 2017).

The characteristic muscle weakness of the intensive care unit is caused by polyneuropathy and/or myopathy of the critically ill patient. Polyneuropathy is the result of axonal degeneration, which is caused by microvascular changes in the endoneuro and allows toxic factors to enter the nerve endings. The resulting edema can affect the energy supply to the axon after the axon has died. Myopathy, in turn, is caused by reduced synthesis and/or increased breakdown of muscle proteins, leading to muscle atrophy (Needham et al., 2010). In addition, immobility is able to change the muscle fibres from slow to rapid contraction, further reducing the patient's muscle resistance (Mota et al., 2012; Beach et al., 2017). Patients admitted to intensive care units are at high risk of muscle weakness and consequently functional disability (Koo et al., 2016; Anakwe et al., 2017). The prolonged immobility that these patients are confronted with causes several systemic complications, especially in the case of musculoskeletal complications. Bed restriction can lead to muscle weakness 
affecting both peripheral skeletal and respiratory muscles (Mota et al., 2012; Hermans et al., 2015; Machado et al., 2017). Facts confirmed by the E3 study, which concluded that early mobilisation reduces the incidence of acquired weakness in the ICU, shortens the days of invasive ventilation, increases the number of patients discharged and the number of patients acquiring faster walking ability. Immobility impairs the action of the respiratory muscles, reduces the diaphragm's ability to generate force and contributes to an increase in immobility, dyspnea and hypercapnia (Dantas et al., 2012; Ishida et al., 2017). Early mobilisation can reduce these adverse effects of prolonged bed rest, as exercise can increase patient functional recovery, self-perception of functional status and quadriceps strength at discharge from hospital if initiated early in patients with prolonged hospitalisation in intensive care (Burtin et al., 2009). In study E1, where the effects of early mobilisation were beneficial, these results were assessed on the basis of the number of rehabilitation consultations, length of stay and full follow-up visits. The introduction of a protocol for early mobilisation in intensive care units has reduced the length of stay and thus the cost of admission. This study suggest that a protocol should be implemented. These facts are present in all the studies, but Study E5 proposes an increase in human resources and the development of a specific protocol, which should be implemented and properly tested, and also in Study E6, which suggests that this procedure should be carried out routinely using protocols between nurses and physiotherapists.

In addition, Stiller (2007) reports that in critically ill patients, mobilisation can reduce the incidence of lung complications, speed recovery and shortened the duration of mechanical ventilation and hospital stays. This shows that both patient health and cost reduction can be optimised by early mobilisation. As shown in Study E1, where the effects of early mobilisation were beneficial, these results were assessed on the basis of the number of rehabilitation visits, length of stay and full follow-up. The introduction of a protocol for early mobilisation in the intensive care unit has made it possible to reduce the length of stay and therefore the cost of admission. You suggest that a protocol should be implemented.

In addition to the reduction in the length of stay in the ICU, the Soares study (et al., 2010) showed a $45 \%$ reduction in mortality (as referred to in study E3), a fact linked to the withdrawal of patients from bed, which, in conjunction with early mobilisation, was able to restore functional limitations and reduce dysfunctions and morbidity. Wang et al (2018) showed a $2 \%$ reduction in mortality, probably due to the fact that the intervention group received respiratory physiotherapy once a day in conjunction with other treatment, such as early mobilisation, and the control group was only supervised by other members of the ICU team, which normally included aspiration only. This fact can be found in all studies, especially in study E6, which refers critically ill patients who undergo early mobilisation, have greater muscle strength and fewer days of mechanical ventilation, and in one study which shows that the short-term effects are a sufficient incentive for early mobilisation in ICU patients.

Regarding delirium, Schweickert et al (2009) showed a two-day reduction in the intervention group through daily sedation interruption and early mobilization, compared to the control group, which underwent daily sedation interruption and standard care.

The gain in muscle strength was verified by Dantas et al. (2012) by comparing two groups, one of which underwent conventional physiotherapy with daily care five times a week, with the development depending on the patient's response, while the other underwent early mobilization, systematized twice a day, every day of the week, resulting not only in a gain in muscle strength in the quadriceps, but also in a gain in inspiratory muscle strength. These gains lead us to the conclusion that a broader view of the patient's functional recovery aspect is needed (Walsh et al., 2014). In some articles the observed results were compatible with the search. We also found that the presence of barriers such as sedation, physiological instability and hospital environment often prevents the implementation of the early mobilization protocol (Gomes et al., 2012). He refers to study E2, which recognizes the added value of early mobilization but notes that there are several factors that may limit this procedure, and study E5, which notes that this challenge of early mobilization is due to the specificities of the critically ill patient (vasoactive support, hypersedation, ventilation). As in Study E4, which states that the refreshment of the fact that early mobilization has several advantages is a major challenge, as it has been possible to verify the shortage of professionals, the lack of time for mobilization procedures and the increased risk of self injury. In addition to these factors, it also highlights the particularities of critically ill patients, often sedated and delirious. And also in study E6 which identifies as main barriers the lack of availability of professionals, the risk of self-injury, the challenge itself and the characteristics of the patient, often sedated and in delirium. On these grounds, haemodynamically unstable patients who require high doses of vasopressors are not fit to start or advance in the therapy (Abrams et al., 2014; Almeida et al., 2014). The same was the case for the results corresponding to haemodynamic stability, mentioned in seven studies, and the lack of use of vasoactive drugs, cited by four authors. As it refers study E5.

For it to be considered as a priority, EM, as a strategy to improve the rehabilitation outcomes of critically ill patients, it also involves a cultural change in the healthcare team towards a patient-centred care approach. To this end, the use practices should be reviewed, the obstacles and constraints in the multidisciplinary team identified, and the advantages arising from the adoption of a strategy requiring more interaction with the patients and more participation of the patients in their rehabilitation process should be understood. This facts corroborate with Study E7 that suggests that motivation of the health team can be related to doubts, workload and fears, as well as study E5 that reveals the division of ideas, for although clinical practice guidelines point to the multiple benefits of early mobilization, it is a challenge to implement them.

It was found that safety issues should be considered before mobilizing critically ill patients. From the analysis of the articles it was observed that it is possible to mobilize the patient safely and without serious complications, however, there are some barriers to be overcome, which is why there is a need for further studies on the subject.

\section{V.CONCLUSION}

This publication is licensed under Creative Commons Attribution CC BY.

http://dx.doi.org/10.29322/IJSRP.10.12.2020.p10810

WwW.ijsrp.org 
ISSN 2250-3153

Concerning the results of the studies analysed, it can be noticed that patients undergoing early mobilization in a safe and viable manner have benefits in the face of the disease and its recovery. This conduct contributes to the reduction of muscle weakness acquired by immobility in bed, allowing a faster functional recovery, shorter weaning, and hospital and ICU stays, always safeguarding the patient's safety.

Early mobilization as therapeutic conduct has room in the rehabilitation and treatment of the critical patient ICU. Motor rehabilitation at ICU targets functional independence and improves the quality of life.

Complications from immobilization in ICU are numerous, unhealthy, and develop a reduction in functional fitness, which directly affects the quality of life of the individual, consequently increasing their stay in the hospital, and relates to worrying degrees of morbidity and mortality. However, protocols and human resources must be guaranteed so that this procedure can be properly performed.

\section{REFERENCES}

1. Abrams, D., Javidfar, J., Farrand, E., Mongero, L., Agerstrand, C., Ryan, P., et al (2014). Early mobilization of patients receiving extracorporeal membrane oxygenation: a retrospective cohort study. Crit Care. 18(1).

2. Almeida, K., Novo, A., Carneiro, S., Araújo, L. (2014). Análise das variáveis hemodinâmicas em idosos revascularizados após mobilização precoce no leito. Rev Bras Cardiol, 27(3), 165-71.

3. Anekwe, E., Koo, K., Marchie, M., Goldberg, P., Jayaraman, D., Spahija, J. (2017). Interprofessional survey of perceived barriers and facilitators to early mobilization of critically ill patients in Montreal, Canada. J Intensive Care Med.

4. Beach, L., Fetterplace, K., Edbrooke, L., Parry, S., Curtis, R., Rechnitzer, T. et al (2017). Measurement of physical activity levels in the Intensive Care Unit and functional outcomes: An observational study. J Crit Care. 40, 189-196.

5. Benefield, L. (2003). Implementing evidence-based practice in home care. Home Healthcare Nurse, 21, 804-811.

6. Burtin, C., et al (2009). Early exercise in critically ill patients enhance short-term functional recovery. Crit Care Med., 37, 24992505.

7. Constantin, J. (2016). Early Mobilisation in ICU: From Concept to Reality - Four Steps to Change Patient Outcomes. ICU management and practice, 16-44.

8. Dantas, C., Silva, P., Siqueira, F., Pinto, R., Matias, S., Maciel, C., et al. (2012). Influência da mobilização precoce na força muscular periférica e respiratória em pacientes críticos. Rev Bras Ter Intensiva, 24(2) 173-178.

9. Escalon, M., Lichtenstein, A., Posner, E., Spielman, L., Delgado, A., et al (2020). The Effects of Early Mobilization on Patients Requiring Extended Mechanical Ventilation Across Multiple ICUs. Crit Care Explor. 2(6)119.

10. Feliciano, V., Albuquerque, C., Andrade, F., Dantas, C., Lopez, A., et al (2012). A influência da mobilização precoce no tempo de internamento na Unidade de Terapia Intensiva. Assobrafir Ciência, 3(2) 31-42.

11. Fontela, P., Forgiarini, L., Friedman, G. (2018). Clinical attitudes and perceived barriers to early mobilization of critically ill patients in adult intensive care units Rev Bras Ter Intensiva. 30(2), 187-194. doi: 10.5935/0103-507X.20180037

12. Grap, M., \& McFetridge, B. (2012). Critical care rehabilitation and early mobilisation: An emerging standard of care. Intensive and Critical Care Nursing, 28, 55-57.

13. Gomes, J., Martins, M., Gonçalves, M., \& Fernandes, C. (2012). Enfermagem de reabilitação: Percurso para a avaliação da qualidade em unidades de internamento. Revista de Enfermagem Referência, 8, 29-38.

14. Hermans, G., Berghe, G. (2015). Clinical review: intensive care unit acquired weakness. Crit Care, 19(1).

15. Hodgso, C., Capell, E., Tipping, C. (2018). Early Mobilization of Patients in Intensive Care: Organization, Communication and Safety Factors that Influence Translation into Clinical Practice Crit Care.20, 22(1),77. doi: 10.1186/s13054-018-1998-9.

16. Ishida, H., Suehiro, T., Watanabe, S. (2017). Comparison of abdominal muscle activity and peak expiratory flow between forced vital capacity and fast expiration exercise. J Phys Ther Sci, 29(4), 563-6.

17. Koo, K., Choong, K., Cook, D., Herridge, M., Newman, A., et al (2016). Early mobilization of critically ill adults: a survey of knowledge, perceptions and practices of Canadian physicians and physiotherapists. CMAJ, 18(3), 448-54.

18. Machado, A., Neto, R., Carvalho, M., Soares, J., Cardoso, D., Albuguergue, I. (2017). Effects that passive cycling exercise have on muscle strength, duration of mechanical ventilation, and length of hospital stay in critically ill patients: a randomized clinical trial. J Bras Pneumol, 43(2), 134-9.

19. Mah, J., Staff, I., Fichandler, D., Butler, K. (2013). Resource-efficient mobilization programs in the intensive care unit: who stands to win? Am J Surg. 206(4), 488-93.

20. Maheswaran, J., Fromowitz, J., Goldfarb, M. (2020). Early Mobilization Interventions in the Intensive Care Unit: Ongoing and Unpublished Randomized Trials. Critical Care Research and Practice. Article ID 3281394. doi.org/10.1155/2020/3281394.

21. Mattos, S. (2011). Fisioterapia motora no paciente crítico: uma revisão. 2011.Trabalho de conclusão de curso. Especialização em Fisioterapia em Terapia Intensiva. Universidade Católica de Brasília, Brasil.

22. Mendes, A., Fracolli, L. (2008). Revisão sistemática de literatura e metassíntese qualitativa: considerações sobre sua aplicação na pesquisa em enfermagem. Texto Contexto Enfermagem, 17(4), 771-778.

23. Morris, P., Griffin, L., Berry, M., Thompson, C., Hite, D., Winkelman, C., Haponik, E. (2011). Receiving early mobility during an ICU admission is predictor of improved outcomes in acute respiratory failure. The American Journal of the Medical Sciences, 341(5), 373-377.

This publication is licensed under Creative Commons Attribution CC BY.

http://dx.doi.org/10.29322/IJSRP.10.12.2020.p10810

WwW.ijsrp.org 
24. Mota, C., Silva, V. (2012). A segurança da mobilização precoce em pacientes críticos: uma revisão de literatura. Interfaces Científicas - Saúde e Ambiente. 1(1):83-91.

25. Needham, D., Korupolu, R., Zanni, J., Pradhan, P., Colantuoni, E., Palmer, J. et al (2010). Early physical medicine and rehabilitation for patients with acute respiratory failure: a quality improvement project. Arch Phys Med Rehabil, 91(4), 536-542.

26. Oliveira, A., Silveira, T. (2010). Mobilização precoce em UCI. Salutis Scientia - Revista de Ciências da Saúde da ESSCVP, 2.

27. Parry, S., Knight, L., Connolly, B., Baldwin, C., Puthucheary, Z., Morris, P. et al (2017). Factors influencing physical activity and rehabilitation in survivors of critical illness: a systematic review of quantitative and qualitative studies. Intensive Care Med. 43(4) $531-42$.

28. Regulamento $n^{\circ}$ 124, de 18 de fevereiro. Diário da República nº 35/11 - II Série. Ordem dos Enfermeiros. Lisboa, Portugal.

29. Rocha, L., Nascimento, R., Rocha,T., Pinto, M. (2012). Avaliação do benefício do exercício físico moderado na resposta imunológica de ratos submetidos ao estresse de contenção. Motricidade, 8, 1055-64.

30. Rocha, A., Martinez, B., Maldaner, V., Forgiarini, L. (2017). Early mobilization: Why, what for and how?. Medicina Intensiva. 41, 7, 429-436. DOI: 10.1016/j.medin.2016.10.003.

31. Santos, C., Pimenta e Nobre, C. (2007). A estratégia pico para a construção da pergunta de pesquisa e busca de evidências. Revista Latino-Americana Enfermagem, 15(3), 508-511.

32. Schweickert, W., Pohlman, M., Pohlman, A., et al (2009). Early physical and occupational therapy in mechanically ventilated, critically ill patients: a randomised controlled Trial. 30, 373, 1874-82.

33. Silva, A., Maynard, K., Cruz, M. (2010). Efeitos da fisioterapia motora em pacientes críticos: revisão de literatura. Rev Bras Ter Intensiva. 22(1), 85-91.

34. Soares, T., et al. (2010). Retirada do leito após a descontinuação da ventilação mecânica: há repercursão na mortalidade e no tempo de permanência na unidade de terapia intensiva?. RBTI. São Paulo, 22(1).

35. Soares, S., Santiara, M., Guastalla, T. (2011). Terapia rotacional: eixo longitudinal, emunidade de terapia intensiva. Rev. Ciênc. Méd., Campinas, 20 (1-2) 37-45.

36. Stiller, K. (2007). Safety issues that should be considered when mobilizing critically ill patients. Critical Care Clinics, 23, 35-53.

37. Terra, R., Silva, S., Pinto, V., Dutra, P. (2012). Efeito do exercício no sistema imune: resposta, adaptação e sinalização celular. Rev Bras Med Esporte. 18(3), 208-14.

38. Walsh, C., Batt, J., Herridge, M., Dos Santos, C. (2014). Muscle wasting and early mobilization in acute respiratory distress syndrome. Clin Chest Med, 35(4), 811-26.

39. Wang, Y., Haines, T., Ritchie, P., Walker, C., Ansell, T., Ryan, D., et al (2014). Early mobilization on continuous renal replacement therapy is safe and may improve filter life. Crit Care, 18(4).

40. Zhang, L., Hu, W., Cai, Z., Liu, J., Wu, J., et al (2019). Early mobilization of critically ill patients in the intensive care unit: A systematic review and meta-analysis. PLoS One. 14, 10, doi: 10.1371/journal.pone.0223185.

This publication is licensed under Creative Commons Attribution CC BY.

http://dx.doi.org/10.29322/IJSRP.10.12.2020.p10810

WwW.ijsrp.org 